This item was submitted to Loughborough's Research Repository by the author.

Items in Figshare are protected by copyright, with all rights reserved, unless otherwise indicated.

\title{
Photoluminescence imaging analysis of doping in thin film CdS and CdS/CdTe devices
}

PLEASE CITE THE PUBLISHED VERSION

https://doi.org/10.1109/PVSC.2017.8521507

PUBLISHER

IEEE

VERSION

AM (Accepted Manuscript)

LICENCE

CC BY-NC-ND 4.0

\section{REPOSITORY RECORD}

Potamialis, C., Fabiana Lisco, Bianca Maniscalco, Mustafa Togay, Ali Abbas, Martin Bliss, Jake W. Bowers, et al.. 2019. "Photoluminescence Imaging Analysis of Doping in Thin Film Cds and Cds/cdte Devices". figshare. https://hdl.handle.net/2134/27047. 


\title{
Photoluminescence imaging analysis of doping in thin film CdS and CdS/CdTe devices
}

\author{
C. Potamialis ${ }^{1}$, F. Lisco $^{1}$, B. Maniscalco ${ }^{1}$, M. Togay ${ }^{1}$, A. Abbas ${ }^{1}$, M. Bliss ${ }^{1}$, J.W. Bowers ${ }^{1}$, J.M. Walls ${ }^{1}$ \\ I. Rimmaudo², R. Mis Fernandez², V. Rejon², J.L. Peña ${ }^{2}$ \\ ${ }^{1}$ CREST, Wolfson School of Mechanical, Electrical and Manufacturing Engineering, Loughborough \\ University, Loughborough, UK \\ ${ }^{2}$ Cinvestav, Unidad Merida, Merida, Yucatan 97310, Mexico
}

\begin{abstract}
The use of photoluminescence (PL) imaging analysis to assess the effectiveness of the passivation treatment due to the presence of chlorine in CdS thin films has been investigated. In this work, we show that the chlorine doping effect in the CdS window layer can be detected by PL imaging analysis, due to the formation of a defect complex of sulfur vacancy and $\mathrm{Cl}_{\mathbf{s}}\left(\mathrm{V}_{\mathrm{s}}-\mathrm{Cl}_{\mathrm{s}}\right)$ and complexes between halogen ions and cadmium vacancies $\left(\mathrm{V}_{\mathrm{Cd}^{-}}\right.$

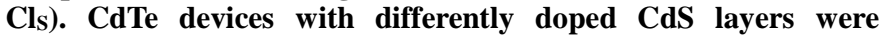
investigated. PL imaging, TEM, IV performance indicators and EQE analysis were performed to understand the effect of the different dopants on the electrical performances of $\mathrm{CdTe}$ devices.
\end{abstract}

\section{INTRODUCTION}

Thin film CdTe solar cells are already a commercially successful technology, due to a combination of low processing costs, and high module efficiency. The current efficiency record is $22.1 \%$ by First Solar [1], where an important step in the device fabrication is the $\mathrm{CdCl}_{2}$ post annealing treatment. The $\mathrm{CdCl}_{2}$ treatment is necessary to produce high performing devices due to the beneficial structural and electrical impact on $\mathrm{CdS} / \mathrm{CdTe}$ heterojunction devices. However, a weak $\mathrm{CdCl}_{2}$ activation treatment results in poorly passivated grains, limiting the performance of the device, whilst an aggressive $\mathrm{CdCl}_{2}$ activation process can cause excessive consumption of the CdS layer and may damage the junction with excessive chlorine build up at the interface [2], leading to delamination [3]. Usually optimization of this process consists of assessing the performance of completed devices which can be very time consuming and not cost effective.

Photoluminescence (PL) imaging is a powerful technique which allows fast, non-contact device analysis at each step of the fabrication process. This technique is suitable for large scale manufacturing use and assists the quest for further cost reduction of CdTe solar cells [4].

Commonly in CdS/CdTe solar cells, PL spectra peaks in the range of $1.3-1.5 \mathrm{eV}$ originates from $\mathrm{CdTe}$, while peaks in the range of $1.9-2.2 \mathrm{eV}$ are related to CdS [7]. When the CdS is subjected to the $\mathrm{CdCl}_{2}$ annealing treatment, a broad PL emission is generated at around $1.7 \mathrm{eV}$, which is associated with a defect complex of a sulfur vacancy and $\mathrm{Cl}_{\mathrm{S}}\left(\mathrm{V}_{\mathrm{S}}-\mathrm{Cl}_{\mathrm{S}}\right)$ [5][6]. $\mathrm{CdCl}_{2}$ activation introduces large amounts of $\mathrm{Cl}$ atoms which may occupy sulfur vacancies and introduce the $\mathrm{Cl}_{\mathrm{S}}$ states. Additionally, deep and shallow states are formed since complexes between halogen ions and cadmium vacancies are also likely to occur $\left(\mathrm{V}_{\mathrm{Cd}^{-}}-\mathrm{Cl}_{\mathrm{s}}\right)$ [6]. The emission signal generated by the presence of chlorine in CdS films can be detected by PL imaging. This analysis can provide useful information about the effectiveness of the $\mathrm{CdCl}_{2}$ treatment in $\mathrm{CdS} / \mathrm{CdTe}$ devices even before the application of the back contact.

In this report, PL Imaging analysis was used to investigate the effect of different chlorine dopants in the CdS thin films used for CdTe solar cells. $\mathrm{CdCl}_{2}$ treatment followed by annealing is known to improve the structural and electrical properties of $\mathrm{CdS}$ [6], as well as CdTe. Here we have used different chlorine dopants to understand whether the same improvements could be achieved on the as deposited CdS layer and on the electrical performance of the CdTe devices. The resulting electrical characteristics were studied against the presence of the various chlorine dopants.

\section{Methodology AND EXPERIMENTAL PROCEDURES}

\section{A. PL imaging analysis}

PL imaging was carried out using the system shown in Fig. 1. A 405nm LED was used as the excitation source, with a Si CCD camera fitted with a $720 \mathrm{~nm}$ long-pass filter used to detect the PL signal. The exposure time for all of the measured samples was kept at 10 seconds. All measurements were taken at room temperature and with the sample positioned with the glass facing the camera.

Fig. 2 shows the PL images of as-deposited CdS and CdS following a wet- $\mathrm{CdCl}_{2}$ treatment. PL image acquisition shows the effect of the treatment on the film. The intensity of the signal (pixel counts) was used to compare untreated and treated material (Fig.2). When the $\mathrm{Cl}$ signal is not detectable the image appears completely dark as shown in the response from the untreated material. High intensity signals result in a brighter image, indicating the presence of chlorine complex emission from the $\mathrm{CdCl}_{2}$ treated material. Using the scale bar as a reference, the intensity of $\sim 1000$ counts corresponds to 
untreated material and $\sim 65,000$ counts (detector saturation limit) is typical for a heavily treated layer.

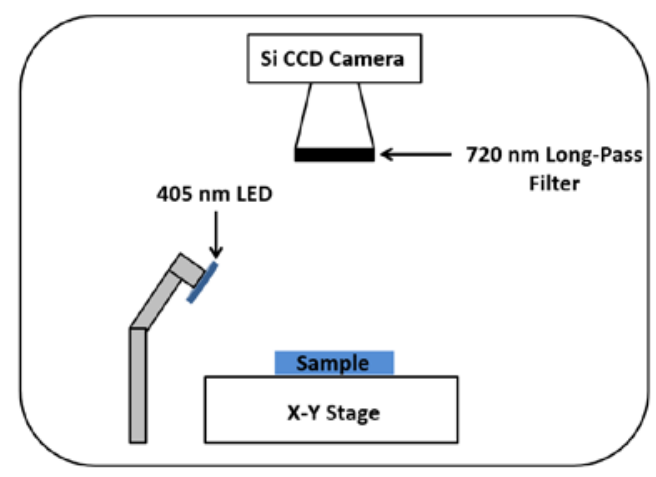

Figure 1: PL imaging system schematic diagram.

These values have been used to establish two extremes of the range and to investigate the performance and homogeneity of the passivation treatment.

During the $\mathrm{CdCl}_{2}$ activation treatment, Te diffuses into the CdS to form a $\mathrm{CdS}_{1-\mathrm{x}} \mathrm{Te}_{\mathrm{x}}$ layer. This creates a broad PL emission in the range of 1.6-1.8 eV [5]. However, since the CdTe was not present, the contribution from Te diffusion into the CdS is removed and therefore the detected signal is due to the presence of chlorine in the CdS film. We believe that chlorine is responsible for the formation of sub band gap $\mathrm{V}_{\mathrm{s}}-\mathrm{Cl}_{\mathrm{s}}$ and $\mathrm{V}_{\mathrm{Cd}^{-}}$ $\mathrm{Cl}_{\mathrm{s}}$ complexes in the CdS [6].

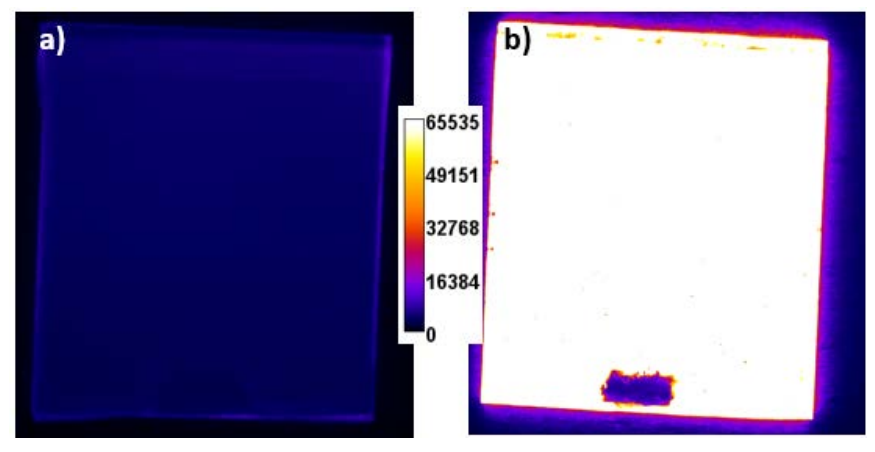

Figure 2: PL images of as deposited CdS (a) and $\mathrm{CdCl}_{2}$ treated CdS (b) thin films.

Fig. 3a) shows the same sample as in Fig. 2, however after the deposition of the CdTe layer. The average PL signal decreased to $1.42 \times 10^{4}$, due to the formation of the $\mathrm{p}-\mathrm{n}$ junction. This results in consumption of the CdS layer, therefore the detection of $\mathrm{V}_{\mathrm{s}}-\mathrm{Cl}_{\mathrm{s}}$ and $\mathrm{V}_{\mathrm{Cd}}-\mathrm{Cl}_{\mathrm{s}}$ complexes, by PL imaging, was limited and the PL emission showed a reduced signal. In Fig. 3b) The same sample after the $\mathrm{CdCl}_{2}$ passivation treatment is illustrated. The average PL counts increased to $4.93 \times 10^{4}$ as a direct result of reintroduction of $\mathrm{Cd}$ and $\mathrm{Cl}$ in the $\mathrm{CdTe}$ device, which diffused into the CdS layer, due to the CdTe activation treatment by evaporation of $\mathrm{CdCl}_{2}$.
PL imagining analysis can be related to the electrical properties of the devices. This investigation was assisted by measuring current density-voltage $(\mathrm{J}-\mathrm{V})$ curves, with the solar cell exposed to AM1.5G, $1000 \mathrm{~W} / \mathrm{m}^{2}$ illumination. EQE measurements were taken using an USHIO UXL-150so Xe Lamp with Newport 67005 lamp housing and H10 Horiba Jobin Yvon monochromator.

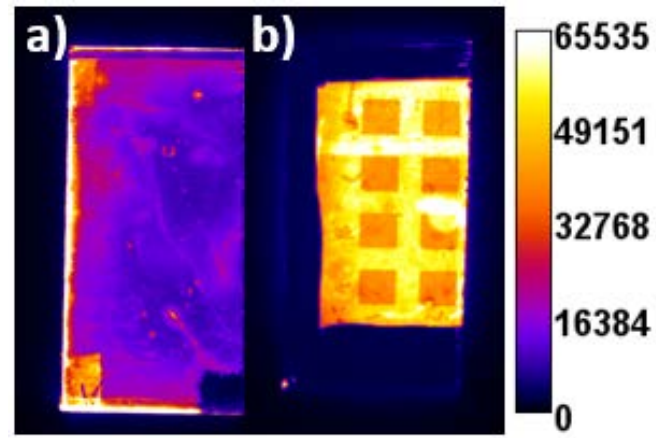

Figure 3: PL images of CdS: a) after CdTe deposition and b) after the second $\mathrm{CdCl}_{2}$ activation treatment.

For a comprehensive analysis of on the effect of the dopants in $\mathrm{CdS}$ on the CdS/CdTe stack, structural investigations were also performed, using a Leo 1530 VP high-resolution field emission gun scanning electron microscope (FEGSEM).

\section{B. CdS thin film deposition by sono-CBD}

The substrates (50x50) $\mathrm{mm}^{2}$ (Pilkington TEC 10, FTO) were ultrasonically cleaned before $\mathrm{CdS}$ deposition, in a de-ionised (DI) water solution containing $10 \%$ acetone and 10\% IPA, for 1 hour at $60^{\circ} \mathrm{C}$. They then received a 5-minute surface activation pre-treatment in an argon and oxygen plasma. CdS thin films were deposited using a sono-chemical bath (sonoCBD) [7], where an ultrasonic probe was used to replace a conventional magnetic stirrer to agitate the bath. $0.01 \mathrm{M}$ $\mathrm{Cd}\left(\mathrm{CH}_{3} \mathrm{COO}\right)_{2}, 0.1 \mathrm{M} \mathrm{CH} \mathrm{N}_{2} \mathrm{~S}, 25$ wt $\% \mathrm{NH}_{4} \mathrm{OH}$ were used as precursors in $200 \mathrm{~mL}$ DI water in a preheated vessel at $70^{\circ} \mathrm{C}$, resulting in films of $\sim 150 \mathrm{~nm}$ thickness [4]. After CdS deposition, the substrates were rinsed with DI water and dried with dry compressed air. CdS doping was carried out using the same procedure, however in each case, alternative chlorine dopants were added to each bath (50\% of the concentration of Cd source), with each deposition lasting for one hour. This resulted in different final thicknesses of the CdS films, according to the dopant added in the bath. In this work $\mathrm{AlCl}_{3}$, and $\mathrm{CdCl}_{2}$ were the investigated dopants. In the case of $\mathrm{CdCl}_{2}$, this was used as a replacement cadmium source to the cadmium acetate used in the baseline process. The presence of $\mathrm{AlCl}_{3}$ in the bath affected the deposition rate of the CdS layer significantly and resulted in an approximately $50 \mathrm{~nm}$ thick film. 


\section{CdTe film deposition by Close Space Sublimation and the $\mathrm{CdCl}_{2}$ activation treatment}

CdTe thin films were deposited in a home-made close-space sublimation system (CSS), using IR lamps, and graphite susceptors [8]. The prepared CdS film and source plate were placed in the vacuum chamber, and separated using quartz spacers. The deposition pressure during sublimation was 1 Torr, with a $6 \% \mathrm{O}_{2}$ in Ar gas mixture. The source and substrate temperatures were rapidly increased, to $630^{\circ} \mathrm{C}$ and $515^{\circ} \mathrm{C}$, and the deposition time was fixed to 3 minutes, which results in 4 to $6 \mu \mathrm{m}$ thick films. The $\mathrm{CdCl}_{2}$ activation treatment was carried out by thermal evaporation. A quartz crucible was loaded with $0.5 \mathrm{~g}$ of $\mathrm{CdCl}_{2}$, which was evaporated at $\sim 1 \times 10^{-6}$ Torr. Postannealing treatment was carried out after thermal evaporation. The samples were annealed on a hot plate at a dwell temperature of $415^{\circ} \mathrm{C}$ for 1 minute with ramping rate of $4^{\circ} \mathrm{C} / \mathrm{min}$ starting from $370^{\circ} \mathrm{C}$. Devices were completed with $80 \mathrm{~nm}$ gold contacts deposited using thermal evaporation, with no intentional copper doping added in this study.

\section{RESULTS}

\section{A. PL imaging analysis on CdS/CdTe devices}

CdS/CdTe devices have been fabricated by varying the dopants in the CdS layer, as described in the experimental section. All samples underwent the same $\mathrm{CdCl}_{2}$ post annealing treatment. Fig. 4 shows the PL image of CdTe devices with un-doped CdS, $\mathrm{CdCl}_{2}$ wet- treated CdS, CdS deposited with $\mathrm{CdCl}_{2}$ as Cd source and CdS: $\mathrm{AlCl}_{3}$.

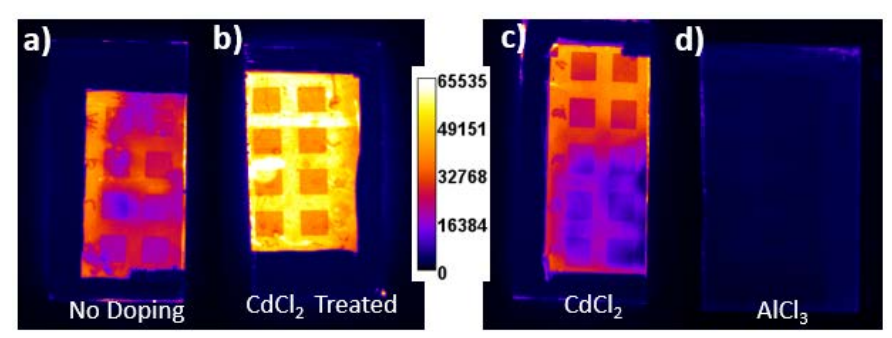

Figure 4: PL images of CdS/CdTe devices with differently doped CdS layers: a) un-doped CdS, b) wet treated CdS c) CdS with $\mathrm{CdCl}_{2}$ as Cd Source and d) CdS: $\mathrm{AlCl}_{3}$

The PL signal was averaged over the 8 individual cells on each sample (each cell has an area of $0.25 \mathrm{~cm}^{2}$ ). The baseline CdS/CdTe structure with no doping in the CdS layer, showed $2.36 \times 10^{4}$ average PL counts with a range of $8.7 \times 10^{3}$ to $4.08 \times 10^{4}$ counts. The CdS which has been $\mathrm{CdCl}_{2}$ wet treated (Fig 4b) showed an average count intensity of $4.93 \times 10^{4}$ (as presented before in the methodology in Fig. 3b). Replacing $\mathrm{Cd}\left(\mathrm{CH}_{3} \mathrm{COO}\right)_{2}$ with $\mathrm{CdCl}_{2}$ as $\mathrm{Cd}$ source, for the deposition of the CdS layer, the average counts remain comparatively the same $\left(2.32 \times 10^{4}\right)$, whilst the maximum PL counts increased up to $\left(4.36 \times 10^{4}\right)$. This can be an indication of a favorable incorporation of $\mathrm{Cl}$ inside the $\mathrm{CdS}$ layer. A low signal intensity was detected for CdS layers doped with $\mathrm{AlCl}_{3}\left(2.2 \times 10^{3}\right.$ average PL counts). This is an indication of either an under treated device, where the incorporation of $\mathrm{CdCl}_{2}$ is almost undetectable or an over treated cell, which resulted in excessive consumption of CdS.

\section{B. Electrical characterization of CdS/CdTe devices}

Fig. 5 shows the J-V curves of CdS/CdTe devices with different CdS layers. The performance of the CdS/CdTe device where CdS layer has been deposited with no additional doping (considered as the baseline structure) gave $10.25 \%$ efficiency with Voc, Jsc and FF of $811 \mathrm{mV}, 19.2 \mathrm{~mA} / \mathrm{cm}^{2}$ and $65 \% \mathrm{FF}$, respectively. Using $\mathrm{CdCl}_{2}$ as the Cd source for the deposition of the CdS layer, the device parameters improved. Efficiency increased to $10.90 \%$ due to an increase in the Jsc (19.9 $\mathrm{mA} / \mathrm{cm}^{2}$ ) and $\mathrm{FF}(67 \%)$ while Voc remained constant (807 $\mathrm{mV})$. This is in agreement with the PL imaging analysis, which showed an increase of the maximum PL counts.

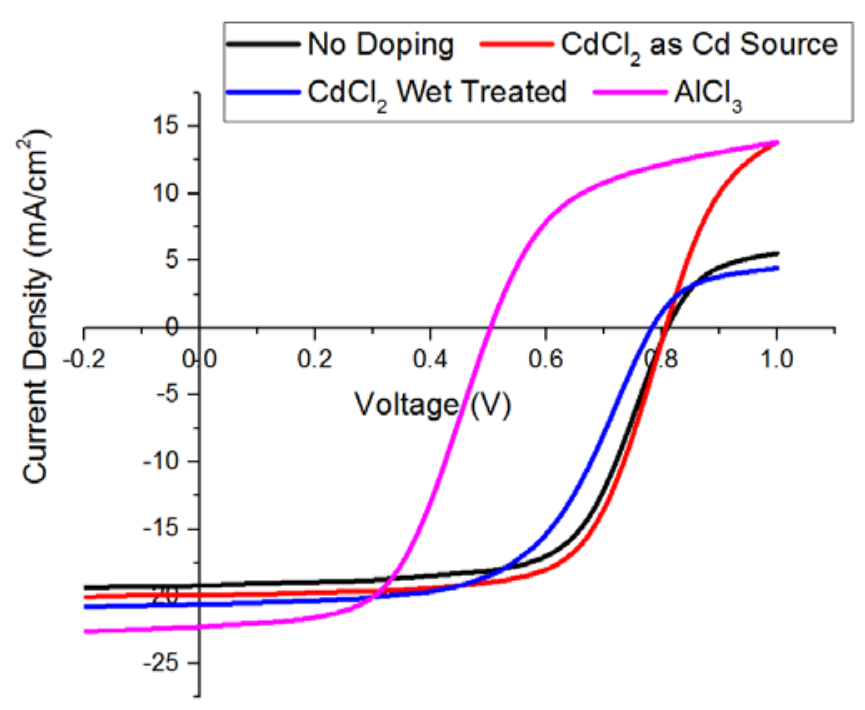

Figure 5: J-V curve of CdS/CdTe devices with different CdS doped layers (un-doped CdS, CdS with $\mathrm{CdCl}_{2}$ as Cd Source, CdS: $\mathrm{ZnCl}_{2}$, wet treated CdS and $\mathrm{CdS}: \mathrm{AlCl}_{3}$ ).

The CdTe device where the CdS layer was $\mathrm{CdCl}_{2}$ wet-treated, prior to CdTe deposition, showed a reduction in electrical performance. The efficiency, Voc and FF decreased to 9.46\%, $784 \mathrm{mV}$ and $58 \%$, respectively. There is a slight increase in current density $\left(20.6 \mathrm{~mA} / \mathrm{cm}^{2}\right)$. PL imaging analysis showed an average of $4.93 \times 10^{4}$ counts, which was significantly higher in comparison to the other investigated devices. However, this sample cannot be directly compared, since it has been undergone a double $\mathrm{CdCl}_{2}$ treatment (before and after the deposition of CdTe). Additionally, since the wet activation treatment performed on CdS films was not totally uniform, this 
could have affected the final performances of the device. In fact, in agreement with the PL imaging analysis, SEM results showed some areas completely depleted of CdS, as an effect of the over treatment. Doping CdS with $\mathrm{AlCl}_{3}$ had a deleterious effect on the overall performance of the device. Efficiency, Voc, and FF decreased to $6.20 \%, 504 \mathrm{mV}$ and 0.55 , respectively. The significant decrease in voltage $(\sim 300 \mathrm{mV}$ reduction compared with the baseline device) indicated a poor p-n junction formation. This was also confirmed by the PL image analysis where the PL emission showed $2.2 \times 10^{3}$ counts.

\section{External Quantum Efficiency (EQE)}

Fig. 6 shows the normalised external quantum efficiency (EQE) analysis performed on the investigated devices. The baseline CdTe structure with the un-doped CdS layer and the CdS layer deposited using $\mathrm{CdCl}_{2}$ as source of cadmium showed comparable EQE responses. Only, in the range of 360 to 580 $\mathrm{nm}$ a slight decrease in EQE was observed for the un-doped CdS layer compared to the CdS deposited with $\mathrm{CdCl}_{2}$ in the bath.

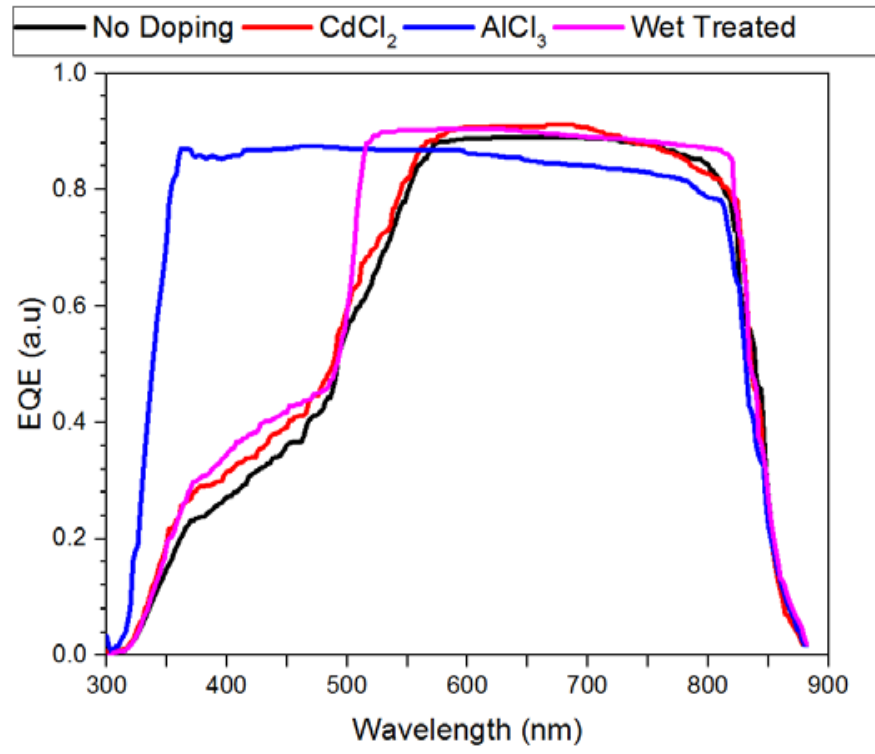

Figure 6: EQE spectra of the investigated samples (un-doped CdS, CdS with $\mathrm{CdCl}_{2}$ as Cd Source, wet treated CdS and CdS:AlCl 3 ).

The CdTe device with the wet treated CdS layer showed a slightly higher EQE in the range of 450-600 nm. Additionally, the EQE response showed less back surface recombination $(700-850 \mathrm{~nm})$ in comparison with the un-doped and $\mathrm{CdCl}_{2}$ doped devices[9]. The CdTe device with $\mathrm{CdS}: \mathrm{AlCl}_{3}$ doped layer showed an atypical EQE curve. The dramatic decrease in absorption in the range of 300-540 nm suggests significant consumption of CdS layer during the $\mathrm{CdCl}_{2}$ activation treatment. It must be mentioned that the as deposited CdS layer doped with $\mathrm{AlCl}_{3}$ was only $50 \mathrm{~nm}$ thick, with a consequence that the $\mathrm{CdCl}_{2}$ activation treatment results in the CdS layer becoming fuly consumed. This is also in agreement with the PL imaging analysis, where the PL image gave a low signal of $2.2 \times 10^{3}$ counts.

\section{SEM, EDX TEM and XRD analysis on CdS/CdTe Devices}

To have a comprehensive understanding on how the dopants affect the $\mathrm{CdS} / \mathrm{CdTe}$ interface after the $\mathrm{CdCl}_{2}$ treatment, morphological and structural analyses were carried out. Fig. 7 shows the SEM cross section analysis of the investigated devices, focusing on the CdTe/CdS interface. The baseline structure with the un-doped CdS layer and the CdS deposited with $\mathrm{CdCl}_{2}$ as the cadmium source exhibit uniform CdS layers with an average thickness of $\sim 120 \mathrm{~nm}$ (Fig. 7a,b). Fig. 7c) shows the CdTe/CdS interface with the $\mathrm{CdCl}_{2}$ wet treated $\mathrm{CdS}$ layer. This device showed a non-uniform CdS layer where some areas were completely depleted as an effect of the double treatment, causing shunt-paths in the device. SEM images of the CdTe device with the CdS: $\mathrm{AlCl}_{3}$ doped window layer (Fig. 7e) showed that the CdS layer is barely visible, indicating total CdS consumption during the $\mathrm{CdCl}_{2}$ activation treatment due to the insufficient initial thickness ( $\sim 50 \mathrm{~nm})$.

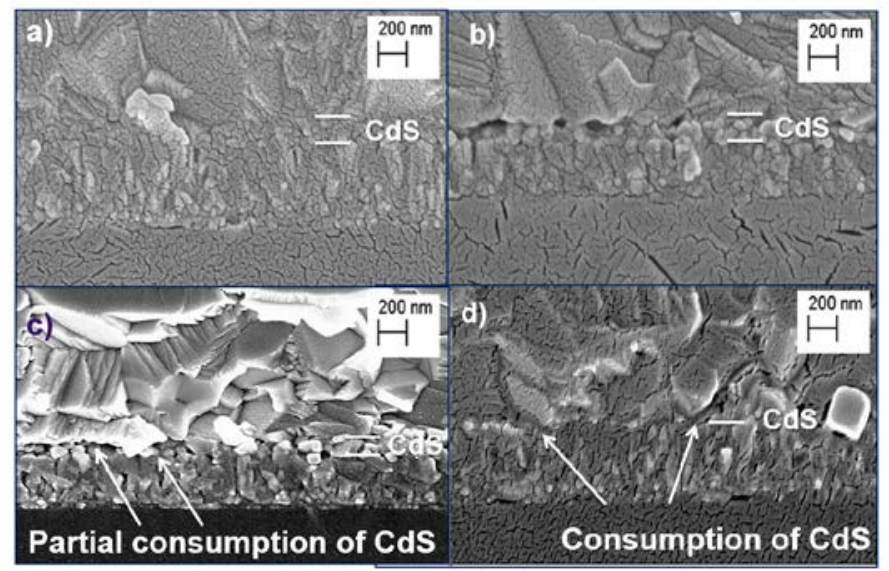

Figure 7: SEM cross section of CdS/CdTe interfaces with: a) un-doped CdS, b) $\mathrm{CdS}$ with $\mathrm{CdCl}_{2}$ as Cd Source, c) wet treated CdS and d) $\mathrm{CdS}: \mathrm{AlCl}_{3}$.

These results agree with PL imaging analysis and electrical performance of the investigated devices.

TEM analysis was also performed on the device where $\mathrm{CdCl}_{2}$ was used as Cd source for the deposition of the CdS layer. This showed the highest PL emission and electrical response. The TEM analysis confirmed the presence of chlorine at the CdTe/CdS interface (Fig. 8) after the $\mathrm{CdCl}_{2}$ activation treatment. This is in agreement with the PL analysis where the chlorine can be detected due to the formation of $\mathrm{V}_{\mathrm{s}}-\mathrm{Cl}_{\mathrm{s}}$ and $\mathrm{V}_{\mathrm{Cd}^{-}}$ $\mathrm{Cl}_{\mathrm{s}}$ complexes which have energy levels in the band gap of the CdS layer. 


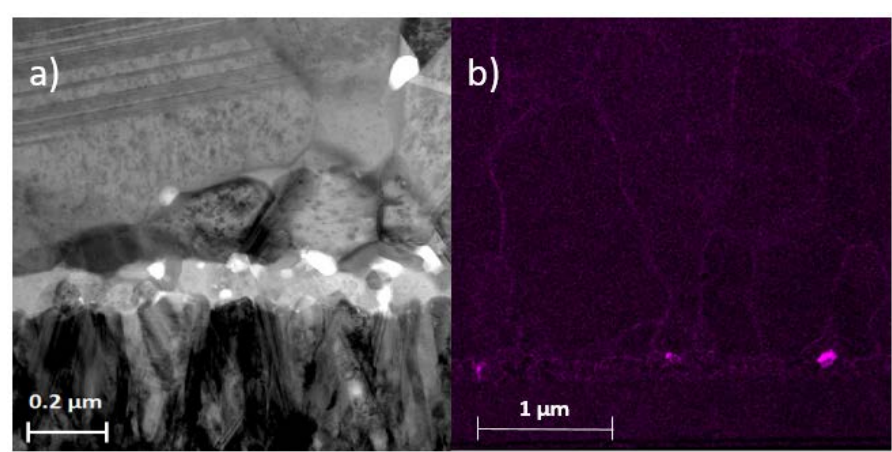

Figure 8: CdS/CdTe device with $\mathrm{CdCl}_{2}$ as source of Cd during CdS deposition a) TEM image and b) chlorine map of the device.

It is known from literature that CdS films exhibit both zincblend (cubic) and wurzite (hexagonal) crystal structure, where the latter is the most stable one [6]. The introduction of dopants in CdS films might influence the crystal growth. Therefore, XRD was performed on all the investigated CdS layers to access any structural change. All the CdS films showed a mixed cubichexagonal structure, except the $\mathrm{CdCl}_{2}$ wet treated layer, which showed the hexagonal phase. Furthermore optical characterisation showed a wider bandgap $(2.4 \mathrm{eV})$ compared to the other investigated samples which can explain the reduction of absorption in the range of $450 \mathrm{~nm}-550 \mathrm{~nm}$.

\section{CONCLUSION}

CdS thin films were deposited by CBD with a variety of different dopants. A comparison was made between CdTe devices where CdS layers were un-doped and doped with $\mathrm{AlCl}_{3}$ and $\mathrm{CdCl}_{2}$. These devices were subjected to the same $\mathrm{CdCl}_{2}$ activation treatment. The presence of chlorine causes the formation of $\mathrm{V}_{\mathrm{S}}-\mathrm{Cl}_{\mathrm{S}}$ and $\mathrm{V}_{\mathrm{Cd}^{-}}-\mathrm{Cl}_{\mathrm{S}}$ complexes in the sub band gap of the CdS material. PL imaging analysis was used to detect the emission originated from these complexes. It has been verified that the PL signal is related to the presence of chlorine when the CdS film was treated with $\mathrm{CdCl}_{2}$, prior to the deposition of CdTe.

It has been shown that the presence of different chorine dopants $\left(\mathrm{CdCl}_{2}, \mathrm{AlCl}_{3}\right)$ in CdS films affected the PL emission signal, once the $\mathrm{CdCl}_{2}$ treatment was performed on the final device.

Furthermore, PL emission was found to be useful to provide qualitative information about the effectiveness and the uniformity of the $\mathrm{CdCl}_{2}$ treatment on the investigated $\mathrm{CdTe}$ devices.

Morphological and structural characterization has been also performed to have a comprehensive understanding on the role of the dopants on the final performance of the solar cells.

Further investigation using alternative dopants may lead to improvement of devices performances. Even though PL was proved to be a powerful tool in the assessment of different CdS dopants use, deeper characterization could enlarge the understanding on the process.

\section{REFERENCES}

[1]
First Solar. Inc, “FIRST SOLAR ACHIEVES YET ANOTHER CELL CONVERSION EFFICIENCY WORLD RECORD,” February 23, 2016. [Online]. Available: http://investor.firstsolar.com/releasedetail.cfm?ReleaseID=9 56479. [Accessed: 01-Jan-2001].

L. D. L. Kranz, "Role of impurities and pn junction formation in CdTe thin film solar cells,” no. 21826, 2014. D. R. Hodges, "Development of CdTe thin film solar cells on flexible foil substrates," University of South Florida, 2015.

T. Trupke, B. Mitchell, J. W. Weber, W. McMillan, R. A. Bardos, and R. Kroeze, "Photoluminescence imaging for photovoltaic applications,” Energy Procedia, vol. 15, no. 2011, pp. 135-146, 2012.

A. E. Abken, D. P. Halliday, K. Durose, A. E. Abken, D. P. Halliday, and K. Durose, "Photoluminescence study of polycrystalline photovoltaic CdS thin film layers grown by close-spaced sublimation and chemical bath deposition Photoluminescence study of polycrystalline photovoltaic CdS thin film layers grown by close-spaced sublimation and,” J. Appl. Phys., vol. 64515, 2009.

L. Wan, Z. Bai, Z. Hou, D. Wang, H. Sun, and L. Xiong, "Effect of $\mathrm{CdCl} 2$ annealing treatment on thin CdS films prepared by chemical bath deposition,” Thin Solid Films, vol. 518, no. 23, pp. 6858-6865, 2010.

F. Lisco, P. M. Kaminski, A. Abbas, K. Bass, J. W. Bowers, G. Claudio, M. Losurdo, and J. M. Walls, "The structural properties of CdS deposited by chemical bath deposition and pulsed direct current magnetron sputtering," Thin Solid Films, pp. 2-6, 2014.

C. Potamialis, F. Lisco, J. W. Bowers, and J. M. Walls, "Fabrication of CdTe Thin Films by Close Space Sublimation,” in PVSAT-12 UoL, 2016.

J. Nelson, The Physics of Solar Cells, First Edit. London: Imperial Collage Press, 2003. 